https://doi.org/10.48009/2_iis_2005_358-363

\title{
THE VARIATION IN THE USE OF ERP SOFTWARE IN THAILAND
}

\author{
Dr. Prachit Hawat, Chulalongkorn University, prachit@acc.chula.ac.th \\ Sarun Chookhiatti, Chulalongkorn University, sarun@acc.chula.ac.th
}

\begin{abstract}
This study explores how ERP software is used. Such an understanding will provide the basis for future studies that look at the productivity and effectiveness of the use of the integrated business software package. Eighteen SAP users, representing 117 companies in Thailand, filled out the questionnaires or gave an interview on the use of the SAP ERP in their companies. In addition, two SAP consultants from two firms were interviewed to gain more insight into the use. Even though ERP systems are designed to be used as and to provide benefit of integrated software packages, selectivity of use is quite common in the use the software. The results indicate that among 11 modules available in the ERP, none of the organizations used all the modules. Financial Accounting (FI) module was the only one used by all the companies in this study. Materials Management (MM), Controlling (CO), and Asset Accounting (AA) modules were used by most of the companies in this study; Sales and Delivery (SD) was used by 63 percent of the companies; Plant Maintenance (PM) by38 percent; Human Resource (HR) by 17 percent; Production Preparation (PP) and Quality Management (QM) were used by less than 10 percent. Project System (PS) was used by a company whereas Workflow (WF) was not used at all. Moreover, SAP was used in conjunction with other software such as MS Excel, Cognos, Hyperion, data warehouse, .Net and in-house developed software. The concepts of relative advantage and technology appropriation were used to explain such variation in the use of the ERP system.
\end{abstract}

Keywords: ERP, Thailand, relative advantage, technology appropriation

\section{INTRODUCTION}

Integrated software packages are one of the current trends in business software industry. One well-known type of integrated business software packages of the past ten years has been enterprise resource planning (ERP). ERP is "a software with an integrated set of applications for enterprise-wide use in functional areas such as finance and accounting, human resource management, manufacturing and logistics" [13]. Such software, if installed across an enterprise, can transmit and share common data among all business units. SAP (the leading ERP software package) includes the following major modules and primary functions:

FI - G/L, A/R, A/P, assets, cash management, and financial reports

MM - purchasing, inventory management, invoice verification, and reports

$\mathrm{CO}$ - cost center, internal order, profit center, planning, and reports

SD - sales, distribution, invoice, and reports

$\mathrm{PM}$ - equipment maintenance

AA - fixed asset register, depreciation, and reports

$\mathrm{PP}$ - production control, MRP, routing instruction on factory floor, reports

QM - quality management

HR - employee master data, training records, payroll, reports 
PS - project system, project cost control, work breakdown, reports

WF - workflow

ERP software was designed with the concept of the benefit of seamless integration to streamline transaction-processing tasks across an enterprise. While ERP software is touted to provide tremendous benefits to the organizations that use them, there are numerous anecdotes about the success and failure resulting from their use $[3,4,5,11]$. What has been largely unexplored is the nature of the use that plays an important role in determining the productivity and effectiveness of the use as well as success and failure of the implementation and use.

This paper reports the preliminary result of an exploratory study of SAP use in Thailand. The purpose of this study is to explore how the ERP software is used. Such an understanding will provide the basis for some future research on productivity and effectiveness of the use of ERPs. The next section of the paper describes research methodology. The results are reported in the third section. The final section summarizes the results and suggests directions for future research.

\section{METHODOLOGY}

This study uses a mixed methodology approach. The research was carried out in three stages. In the first stage, SAP users from three different companies were interviewed to gain an understanding of the way SAP was used in those organizations.

In the second stage, a semi-structured questionnaire was developed based on the information received from the interviews. The questionnaire asked about the use and non-use of various modules, the reasons for non-use, and the benefits of and problems in using the ERP. The questionnaire was sent to eighteen informants who are SAP users in Bangkok, Thailand. Seventeen of them come from seventeen different companies, including the three interviewed in the first stage; the other one is from a group of 100 companies. The group includes various industries such as tiles, paper, petrochemical, cement, and glass. The sampling technique used is convenient sampling; that is, all the informants are either acquaintances of the researchers or people referred by the acquaintances to be the best person to provide information on the use of SAP. Their job positions include Senior Accountants, MIS/IT Managers, Internal Audit Managers, and a Group Accounting Manager. The companies included in this sample are in the majority of Thai companies that use SAP: currently the total number of Thai companies using SAP is about 180. The sample consists of a wide range of industries such as shipping, telecommunications, chemicals, and foods. We excluded subsidiaries or branches of multinational corporations in Thailand because we assume that their use of SAP must be the same as their parent companies or headquarters overseas.

In the third stage, we discussed the information received from the informants with two SAP consultants, from two different firms, to gain additional insight into SAP use and to validate the results. We also confirmed the information on modules used at the group of 100 companies with an accountant in the Group Accounting Department.

\section{RESULTS}

In this study, two patterns of SAP use were found: selectivity of use and use of SAP in conjunction with other software. Each of these patterns will be described in this section. 


\section{Selectivity of Use}

Table 1 shows that SAP users selected certain modules to use. The number of modules used varied from 4 to 9 out of the 11 modules available. The Financial Accounting (FI) module was the only one used by all companies in this study. The Materials Management (MM), Controlling (CO), and Asset Accounting (AA) modules were used by most of the companies. Sales and Delivery (SD) was used by 63 percent of the companies; Plant Maintenance (PM) by 38 percent; Human Resource (HR) by 17 percent; Production Preparation (PP) and Quality Management (QM) were used by 8 and 5 percent, respectively. Project System (PS) was used by one company whereas Workflow (WF) was not used at all.

Table 1. SAP Modules used by each of the companies

\begin{tabular}{|c|c|c|c|c|c|c|c|c|c|c|}
\hline Type of Business & FI & MM & $\mathrm{CO}$ & AA & SD & PM & HR & PP & QM & PS \\
\hline Petrochem Manu 1 & $\mathrm{X}$ & $\mathrm{X}$ & $\mathrm{X}$ & $\mathrm{X}$ & - & $\mathrm{X}$ & $\mathrm{X}$ & $\mathrm{X}$ & - & - \\
\hline Petrochem Manu 2 & $\mathrm{X}$ & $\mathrm{X}$ & $\mathrm{X}$ & $\mathrm{X}$ & $\mathrm{X}$ & $\mathrm{X}$ & $\mathrm{X}$ & $\mathrm{X}$ & $\mathrm{X}$ & - \\
\hline Chem Manu 1 & $\mathrm{X}$ & $\mathrm{X}$ & $\mathrm{X}$ & $\mathrm{X}$ & $\mathrm{X}$ & $\mathrm{X}$ & - & $\mathrm{X}$ & - & - \\
\hline Chem Manu 2 & $X$ & $\mathrm{X}$ & $X$ & $\mathrm{X}$ & $\mathrm{X}$ & $X$ & - & $X$ & $X$ & - \\
\hline Chem Manu 3 & $X$ & $\mathrm{X}$ & $X$ & $\mathrm{X}$ & - & $\mathrm{X}$ & $\mathrm{X}$ & - & - & - \\
\hline Equip Manu 1 & $X$ & $X$ & $X$ & - & $\mathrm{X}$ & $\mathrm{X}$ & - & $X$ & - & - \\
\hline Equip Manu 2 & $\mathrm{X}$ & $\mathrm{X}$ & $X$ & - & $\mathrm{X}$ & - & - & - & - & - \\
\hline Equip Manu 3 & $\mathrm{X}$ & $\mathrm{X}$ & $X$ & - & - & $\mathrm{S}$ & $\mathrm{X}$ & - & $\mathrm{X}$ & - \\
\hline Shipping & $X$ & $\mathrm{X}$ & $\mathrm{X}$ & - & $X$ & $X$ & - & - & - & - \\
\hline Telecom & $X$ & $\mathrm{X}$ & - & - & $\mathrm{X}$ & $X$ & - & - & - & - \\
\hline Tire Manu & $X$ & - & - & - & $\mathrm{X}$ & $X$ & $\mathrm{X}$ & - & - & - \\
\hline Canned Foods 1 & $\mathrm{X}$ & $\mathrm{X}$ & $\mathrm{X}$ & $\mathrm{X}$ & $\mathrm{X}$ & $\mathrm{X}$ & - & $X$ & $\mathrm{X}$ & - \\
\hline Canned Foods 2 & $\mathrm{X}$ & $\mathrm{X}$ & $\mathrm{X}$ & $\mathrm{X}$ & $X$ & $\mathrm{X}$ & - & $X$ & $X$ & - \\
\hline Cement Manu & $\mathrm{X}$ & $\mathrm{X}$ & $\mathrm{X}$ & $\mathrm{X}$ & $X$ & $\mathrm{X}$ & - & $\mathrm{S}$ & - & $\mathrm{S}$ \\
\hline Magarine Manu & $\mathrm{X}$ & $\mathrm{X}$ & $\mathrm{X}$ & - & $\mathrm{X}$ & - & - & $X$ & - & - \\
\hline Trade - Elec App & $X$ & $\mathrm{X}$ & $\mathrm{X}$ & $X$ & $\mathrm{X}$ & $X$ & - & - & $X$ & - \\
\hline Trade - Textile & $\mathrm{X}$ & $X$ & $X$ & - & $\mathrm{X}$ & - & - & - & - & - \\
\hline Constr. Mat. Group & 100 & 100 & 100 & 100 & 60 & 30 & 15 & - & - & - \\
\hline Total Used & 117 & 116 & 115 & 109 & 74 & 44 & 20 & 9 & 6 & - \\
\hline Total Companies & 117 & 117 & 117 & 117 & 117 & 117 & 117 & 117 & 117 & 117 \\
\hline$\%$ & 100 & 99 & 98 & 93 & 63 & 38 & 17 & 8 & 5 & - \\
\hline
\end{tabular}

$\mathrm{X}=$ use; $\mathrm{S}=$ some use $;-$ = non-use

Selectivity of use is an important dimension of use because using and omitting certain functions often result in differences in information quality. Interestingly, one pattern of selectivity found in this study is the use of accounting-related modules (i.e., FI, CO, and AA) by most of the companies, which is similar to that in another Asian country. A recent study of ERP use in Sri Lanka states:

... some large organizations in Sri Lanka have successfully implemented core financial ERP modules such as financials, assets, and planning, budgeting (usually without integrating the main business functions, such as purchasing, inventory and sales) but 
organizations that have adopted more than the core financial modules have experienced problems [8, p. 1382].

The only difference is that most Thai companies use the MM module, which includes purchasing and inventory management, in addition to the accounting-related modules, whereas their counterparts in Sri Lanka do not.

One case of not using certain ERP module was reported in the literature. A canvass of 200 warehouse and information-technology managers indicates that nearly six out of 10 of the companies that had adopted ERP (nearly two-thirds of the respondents) "did not even consider using the ERP system's warehouse module." Many of them used warehouse management system (WMS) software, which is written specifically to manage warehouse operations. They mentioned that "... enterprise resource planning systems are not providing the required functionality for most of today's distribution operations" [2].

In this SAP research, the reasons for selectivity of use, provided by the respondents and the consultants, varied from organization to organization. They include the following:

- Most non-use of HR is due to the fact that the organizations had used some other software such as BPACB on A/S 400, PeopleSoft, or local HRM and payroll software prior to the implementation of SAP. They thought the systems worked fine and there was no need to purchase the HR module from SAP.

- $\quad$ Non-use of WF was because WF was difficult and unecessary to use.

- $\quad$ Non-use of PS by most companies because most of them did not perform project control.

- Non-use of PP by some companies because PP is used for production planning. Thus, the two trading companies did not use PP. In addition, some companies used some other software for production planning.

- $\quad$ Non-use of AA was due to the fact that the companies did not want to create a new asset register in AA while they already had the register either on paper or in some other software.

Further analysis to test the relationship between number of years of SAP use and the number of modules used revealed no relationship, since the company with the longest length of use deployed the least number of modules. The Petrochemical manufacturer No. 1 had used SAP for only 4 months but had used 7 modules, whereas Equipment manufacturer No. 2, after using ERP for almost 5 years, used only 6 modules.

\section{Use SAP in Conjunction with Other Software}

Data collected on the use of SAP also indicated that respondents used SAP in conjunction with other software such as Microsoft Excel, Cognos, Hyperion, PeopleSoft, data warehouse, .Net and in-house developed software. Excel and Cognos were used to develop additional reports for management because some SAP standard reports were not relevant to the requirement of the managers and were therefore difficult to modify. Hyperion was used for performance management. .Net was used for the development of a web application that was linked to the database. With regard to in-house developed software, the accounting department of the group of 100 companies developed their own software to consolidate financial statements of 60 companies in the group. A user in another company mentioned that when a new table had to be 
created, they had to hire an ABAP programmer to write programs for additional reports. The problem of insufficient information from ERP was also voiced in a recent study on two large multinational organization in Great Britain [12]. However, the Group Accounting Manager in the present study mentioned that SAP provided a lot of information, but the only problem was that the reports did not look that nice. The use of SAP in combination with other software has been a common practice for quite some time. It was reported that in 1997 there were about 400 thirdparty vendors of packages, including those of their competitors, which work alongside SAP [1].

The phenomenon of not using certain innovations the way they were designed for is not new. Rogers [10] labelled it "re-invention" and explained that it was originally termed "reinterpretation" in anthropology. Re-invention refers to "the process in which the adopters of an innovation use it in a different way and/or for different purposes than when it was invented or diffused to them" [10, p. 176]. In the present study, both selectivity of use and use in conjunction with other software are definitely re-invention. Re-invention is not uncommon, especially when the innovation is computer-related. For instance, in the study of the adoption of computer-based planning tool GBF/DIME by fifty-three government agencies, some degree of re-invention was found in about half of the units [9]. Moreover, as Rogers [10] pointed out:

an innovation "that is a general concept of that is a tool (like a computer) with many possible applications is more likely to be reinvented... A loose-bundled innovation consists of elements that are not highly interrelated; such an innovation can be flexibly suited by adapters to their conditions" [p.180].

In the field of MIS, a similar concept is present in the area of Group Decision Support Systems (GDSS), which is computer-mediated meeting. Poole and DeSanctis argued that one of the three dimensions of technology appropriation process is whether the group is using the technology faithfully or ironically [7]. Faithful use occurs when the group "stick[s] closely to both the spirit and the specific operations" or when it use GDSS in a way "consistent with the spirit, but change and reinterpret operations" [p. 184]. On the contrary, ironic use involves either using its operations in unintended ways or not complying with both the spirit and operations of GDSS. We can see that ERPs are a somewhat loosely-bundled set of integrated modules that users can easily reinvent to suit their productivity-oriented environment. The use of some ERP modules by a company cannot be considered faithful appropriation, since ERPs are designed to be used as integrated software.

With regard to the benefits of SAP use, in spite of such ironic use, all the informants mentioned a number of benefits such as more information accuracy, faster reporting, more relevant reports, better facilitating of SCM, and enabling standard business processes. Major problems encountered by most informants are inexperienced consultants, bugs in the systems, and high initial costs of the systems and upgrade costs. In addition, an informant raised the problem of errors resulting from transferring data between SAP modules and the manual processes.

\section{CONCLUSION}

Two patterns of SAP use were identified: selectivity of use and use in combination with other software. Selectivity of use can be explained using a relative advantage concept in that the users 
do not select certain modules because costs and the amount of work involved are higher than the benefits from the use as well as the use of SAP in combination with other software.

Future research should investigate how users can make optimal use of the information available in the ERP system by using various additional software packages and how the effectiveness would be in comparison with using ERP per se. In another future research, the impact of national cultures on the use of ERP should be investigated.

\section{REFERENCES}

1. Barrat, W. (March 27, 1997). Products in perspective: The Total Solution, www.pcw.co.uk/analysis/22661 accessed on July 17, 2005.

2. Bradley, P., Thomas, J., Gooley, T. Cooke, J. A. (April 1999). Study: Warehouses need WMS, not ERP systems, Logistics Management \& Distribution Report, 4, 20.

3. Deutch, C. (November 8,1998). Software That Can Make a Grown Company Cry. The New York Times, Business section 3, 1 and 13.

4. Diederich, T. (August 28,1998). Bankrupt Firm Blames SAP for Failure. ComputerWorld.

5. Hunton, J.E., Lippincott, B. Reck, J. L. (August 14-17, 2002). Enterprise Resource Planning (ERP) Systems: Comparing Firm Performance of Adopters and Non-Adopters, Proceedings 2002 Annual Meeting of American Accounting Association, 81.

6. Markus, L. Tanis, C. (2000). The Enterprise Systems Experience--From Adoption to Success, In Zmud, R.W. (Ed.), Framing the Domains of IT Research: Glipsing the Future Through the Past, (pp. 173-207). Cincinnati, OH: Pinnaflex Educational Resources.

7. Poole, M.S., DeSanctis, G. (1990). Understanding the Use of Group Decision Support Systems: The Theory of Adaptive Structuration. In J. Fulk C. Steinfield (Eds.), Organizations and Communication Technology, (pp. 173-191). Newbury Park, CA: Sage.

8. Rajapakse, J. \& Seddon, P. B. (July 7-10, 2005). Why ERP may not be Suitable for Organisations in Developing Countries in Asia, Proceedings of PACIS 2005, Bangkok, 13821388.

9. Rogers, E.M. (1977). Re-Invention of New Ideas During the Innovation Process in Public Organizations. In W. H. Lambright \& J. Carroll (Eds.) Proceedings of a Conference on Technology Transfer to Urban Governments: Agenda for Research and Education, Syracuse University, Maxwell School of Citizenship and Public Affairs.

10. Rogers, E.M. (1983). Diffusion of Innovations (3rd ed.). New York, NY: The Free Press.

11. Shang, S. \& Seddon, P. A. (2000). Comprehensive Framework for Classifying the Benefits of ERP Systems, Americas Conference on Information Systems (AMCIS2000), August 10-13, Long Beach, California.

12. Westrup, C. (March 15, 2005). Four challenges to get the most out of ERP, Computer Weekly, 28.

13. Wilkinson, J.W., Cerullo, M. J., Raval, V. \& Wong-On-Wing, B. (2000). Accounting Information Systems: Essential Concepts and Applications $\left(4^{\text {th }}\right.$ ed.). New York: John Wiley \& Sons. 